\title{
PERSON-ENVIRONMENT MISFIT AND MENTAL DISORDER AMONG PHD STUDENTS: THE MEDIATING ROLE OF MEANINGFUL WORK
}

\author{
Francesco Tommasi, Andrea Ceschi, \& Riccardo Sartori \\ Department Human Sciences, University of Verona (Italy)
}

\begin{abstract}
In organizational psychology, the authors' awareness of the concerns about the current academic working conditions and their potential impacts on PhD students' mental health is increasing. Accordingly, authors have witnessed increased the attention to $\mathrm{PhD}$ students' perception of their fit with the environmental conditions, i.e., organizational policies, co-workers' and supervisors' relations and supports, as an antecedent of their $\mathrm{PhD}$ experience. In particular, such environmental conditions seem to be related to the high diffusion of state anxiety and depression among $\mathrm{PhD}$ students that perceive a certain level of misfit between them and the environment. However, studies suggested that, despite the working conditions, in the presence of positive experience at work, such as meaningful work, individuals are less at risk of developing mental disorders as well as of quitting their job. Indeed, meaningful work construct regards a positive individual phenomenon of experience and perception of meaningfulness at work. Then, it might be a potential experience that might mitigate the experience of negative states at work. The present paper aims to address the current need for knowledge by involving a literature review of the role played by meaningful work in the $\mathrm{PhD}$ experience. Then, the paper explores the potential mediational role of meaningful work between the path from P-E misfit and mental disorders' symptoms and students' intention to quit. A cross-sectional study has been devised via the use of an online questionnaire with self-report measures on P-E misfit, meaningful work, mental health disorders symptoms, and intention to quit. In a sample of $N=251$ Italian $\mathrm{PhD}$ students, the results showed a prevalence of three mental health disorders symptoms, i.e., depression, anxiety and hostility, among doctorate students, which resulted to be positively related to the levels of P-E misfit. Then, the results showed a negative mediating role of meaningful work on the paths from P-E misfit to (a) mental disorders and (b) intention to quit. Finally, the paper advances further steps for research as well as for practical implications for supporting $\mathrm{PhD}$ students.
\end{abstract}

Keywords: PhD students, mental health, intention to quit, meaningful work, doctoral experience.

\section{Introduction}

In organizational psychology, the authors' awareness of the concerns about the current academic working conditions and their potential impacts on $\mathrm{PhD}$ students' mental health is increasing. That seems to be extensively related to the individual perception of fit with the environmental characteristics, such as organizational policies, co-workers' and supervisors' relations, and perception of career progression. Accordingly, studies have disclosed the widespread diffusion of state anxiety and depression among those $\mathrm{PhD}$ students that perceive a certain level of misfit between them and the environment. A low level of perception of person-environment (P-E) fit, namely, P-E misfit, is linked to the risk of having or developing a psychiatric disorder as well as to lead students to quit the doctoral program. However, studies suggested that, despite the working conditions, in the presence of positive experience at work, such as meaningful work, individuals are less at risk of developing mental disorders as well as of quitting their job. Meaningful work regards the individual's own experience of value and significance of one's work. This phenomenon supports the presence of motivation, positive affects at work, and individuals' well-being. However, the knowledge of how and whether the experience of work as meaningful can affect researchers' mental health is limited. This is particularly evident in the literature on the doctoral experiences which have widely overlook the role played by doctoral students' psychological and motivational aspects. 
The present paper intends to propose a comprehension of the role of meaningful work construct in early-career workers in the academic sector, i.e., $\mathrm{PhD}$ students. Given the large concern of mental health among PhD students, meaningful work construct is considered to understand potential factors that might mitigate such relation between the person-environment misfit and negative experience at work. This knowledge results to be relevant both to raise the understanding of $\mathrm{PhD}$ experience and factors as well as to advance further implications for research and applied interventions for students.

To pursue such aim, the contribution comprehends two main sections, in the first of which a literature review on $\mathrm{PhD}$ academic experience and meaningful work is conducted. Secondly, the literature review supported the hypotheses of the role of meaningful work as mediator between (a) mental health and (b) intention to quit. Such hypotheses have been verified by the involving a cross-sectional study in a sample of $N=251$ Italian PhD students. By discussing the results, further implications for research and practice are presented.

\section{Literature review}

Coupling the existing literature on $\mathrm{PhD}$ experience with the evidence in organizational psychology domain, the risk of having or developing a psychiatric disorder as well as to lead students to quit the doctoral program seems to be related to the perception of individual misfit (Ward \& Brennan 2020). The misfit notion belongs to the so-called person-environment fit theoretical approach which conceptualizes the extent to which individuals experience a certain level of fit their job, organization, co-workers (and/or supervisor) as well as their goals and vocation/calling ( $\mathrm{Su}$ et al., 2015). Therefore, misfit sits at nexus between theories on the working environment conditions for the individual to manifest their traits and studies on the fit between individuals and their environment that leads to negative outcomes, e.g., stress and turnover intention. Although no consensus over what P-E fit means, authors agree on the relevance of comprehending and solving career-related issues, organizational conditions that might affect employees' well-being and productivity. That is particularly evident in the case of academics and $\mathrm{PhD}$ students.

Several scientific contributions have recently been published with particular reference to the doctoral experience. In an editorial of Nature Career Blog, the results obtained from various international surveys on the doctoral experience are reported. Among the various dimensions analyzed regarding the contents and training courses, some contextual and psychological aspects were taken into consideration. In the case of the doctoral course, the authors disclose the issue regarding the widespread diffusion of permanent anxiety and depression among students (about $36 \%$ of the population involved) which are found to be aggravated in $45 \%$ of cases by a strong loss of motivation and the intention to leave the workplace. The reasons are manifold but attributable to the mark-factors described above. On the one hand, in $20 \%$ of cases, these states are caused by a competitive and stressful relational climate in which the deterioration of psycho-physical health would be caused by the $\mathrm{PhD}$ students experience of fit with the organization, the job itself and the supervisor relation (Nature Career Blog, 2019; Euroscientist, 2018; Sverdlik et al. 2018).

Therefore, questions arise regarding the possible paths to follow for attempts to resolve the phenomenon. A wide range of proposals is offered in the literature. With an explicit focus on the individual aspect, meaningful work experience, i.e., the positive experience and perception of meaningfulness at work (Rosso et al., 2010), represents a motivational factor that might refer to both the individual daily experience as well as its steady mindset which is predictive of positive outcomes at work (Tommasi et al., 2020). The recent metanalysis proposed by Allan and colleagues (2010) showed the potential mediator role of meaningful work. In this context, meaningful work mitigates the occurrences of negative affect at work such as anxiety, depression and hostility (Steger et al., 2012) as well as turnover intention (Allan et al., 2019).

\section{The present study}

The present study aimed to explore the role of meaningful work experience as a mediator between the relation of Person-Environment misfit and mental health, and turnover intention. A cross-sectional study with self-report measure has been designed to assess the presence of the psychological dimensions considered, i.e., P-E misfit, meaningful work, turnover intention and students mental health. After presenting the study procedure and the hypotheses of the study, the present section reports the participants' description and the instruments used. Then, the results of the study are presented.

In respect of the procedure, the questionnaire was submitted via email and participants were asked to voluntary fill in the questionnaire which was proposed online through LimeSurvey. For the process of the submission, the authors collaborated with the Italian Doctoral Committee Association 
which supported the project. A total of 553 emails were sent by the researchers to $\mathrm{PhD}$ students of 45 Italian universities. Only $303 \mathrm{PhD}$ students participated in the study (response rate, 54.79\%) within whom 251 completed all the questionnaire. After presenting the aim of the study, participants were asked to sign the informed consent to complete the survey. The compilation of the questionnaire required a total of 7-10 minutes.

Then, in respect of the data analysis, the incidence of mental disorder among participants and their intention to quit their job was evaluated by the use of descriptive statistics. Then, data were analyzed with structural equation modelling (SEM) to verify the hypothesized models. To pursue such aim, two separate models have been tested to verify the hypotheses that P-E misfit positively predicts mental disorder and turnover intention (H1). In particular, P-E misfit positively predicts the level of mental disorders (H1a), and P-E misfit positively predicts turnover intention (H1b). The mediation models have been tested with meaningful work as a mediator $(\mathrm{H} 2)$. That is, meaningful work fully mediates the association between P-E misfit and mental disorders (H2a) as well as the association between P-E misfit and turnover intention (H2b). Such analysis was conducted by the use of SPSS and AMOS. Firstly, demographic statistics as well as reliability were conducted via the use of SPSS version 22. Secondly, concerning the model testing, the additional software program used to fit SEM, namely, AMOS.

\subsection{Participants}

$251 \mathrm{PhD}$ students participated in the study (average age, 29.5 years old, $S D=3.91,63.35 \%$, $N=159$ females). Moreover, for the demographic data we also asked participants to report information in regard of (a) their personal characteristics such as their level of education and perceived health (based on 5 points-Likert scales, $1=$ I have very bad health to $5=$ I have very good health) and (b) their working characteristics such as their university/institutions, type of research sector and type of doctoral program (i.e., with/without scholarship, joint $\mathrm{PhD}$ program between Universities and/or private companies). Within the participants, the $66.93 \%$ had a master's degree $(N=168)$, the $27.49 \%(N=69)$ had attained a professionalizing master while the $4.78 \%(N=12)$ reported to already have a $\mathrm{PhD}$. Most of the participants reported to feel that their health was sufficiently well, $36.26(N=91)$, while the $36.1 \%$ $(N=90)$ reported having a medium to high health while the rest $27.64 \%(N=68)$ a bad to a very bad perceived level of health. Participants were from 49 different Italian Universities and the $70.52 \%$ had a three-years scholarship while the $24.3 \%(N=61)$ without a scholarship and the rest $5.2 \%(N=13)$ had a specific scholarship founded by a collaboration between separate universities, international projects or private companies. Within this last group, only four participants (1\%) had a four-years scholarship. Moreover, the study participated in students from the first year in the PhD program. Finally, participants reported being from $N=27$ various and separate macro disciplines, e.g., engineer, medicine, arts and humanities.

3.1.1. Instruments. By the aim of the study measures of P-E misfit, turnover intention and meaningful work were used. Firstly, basing on the literature, P-E misfit were measured by the combination of three its dimensions, namely, P-Job (P-J) misfit (Lauver \& Kristof-Brown 2001), P-Organization (P-O) misfit (Lauver \& Kristof-Brown 2001), and P-Supervisor (P-S) misfit (Chuang et al., 2016). Each measure of fit comprised different items per dimension (i.e., 5 items for P-J misfit, 3 items for P-O misfit and 3 items for P-S misfit) and participants had to report their level of agreement on a 7-point-Likert scale $(1=$ Not at all, $7=$ Totally agree). P-J misfit indicates the extent to which an individual perceives and experiences that their goals doesn't with those of the job based on the contextual conditions. Likewise, P-O misfit involves items which refer to the level to which the individual doesn't recognize themselves in the organizational culture and policies. Finally, P-S misfit assesses the level to which a PhD student doesn't feel to be coherent with the orientation and behaviour of their supervisor. All the P-E misfit resulted to have acceptable reliability indices, i.e., P-J misfit Cronbach' $\alpha=.82$, P-O misfit Cronbach' $\alpha=763$, P-S misfit Cronbach' $\alpha=.925$.

Secondly, for the outcome variables, the Brief Symptom Inventory was used to assess the presence of anxiety, depression and hostility sense among the $\mathrm{PhD}$ students. Such measures comprised a total of six items per dimension reporting specific feelings. Participants had to report the level of the frequencies at which they are used to have such feelings on a scale from $1=$ never to $5=$ very often. Each dimension resulted to have acceptable reliability indexes, i.e., anxiety, Cronbach' $\alpha=.876$, depression, Cronbach' $\alpha=.819$, hostility, Cronbach' $\alpha=.883$. Regarding turnover intention, it was measured with the Bluedorn (1982) intention to quit measure. A self-report measure that assesses the level to which individuals wants to leave their job in the following years basing on a 5-point Likert scale of agreement $(1=$ not at all to $5=$ Totally agree, Cronbach' $\alpha=831$. 
Finally, meaningful work was measured by the use of the modular questionnaire developed by Schnell \& Hoffmann (2020). Such questionnaire comprises three modules, i.e., module 1-sources of meaningful work, module 2-meaningful and meaningless work, and module 3-work as a source of meaning. Notwithstanding the validity of the overall questionnaire, we only used the dimension of meaningful work comprised in module 2. This dimension assesses if individuals perceive that their work is meaningful for them by involving three items. We used the Italian version proposed by Tommasi et al. (under review) and participants had to report their level of agreement on a 7-point Likert scale $(1=$ not at all, 7 = agree, Cronbach' $\alpha=.942$ ).

\subsection{Results}

Before testing our hypotheses, we run descriptive statistics to understand the level of mental disorder and turnover intention among PhD students. Firstly, for a mental disorder, anxiety symptoms were presents in the $39 \%(N=93)$ of the $\mathrm{PhD}$ students, and similarly, depression symptoms were presents in the $31.47 \%$ of the participants $(N=79)$. Hostility symptoms resulted to be fewer presents among the students with the $9.56 \%$ of participants who reported to have moderate to a higher level of their frequencies. By contrast, the level of intention to quit reported to be present in the $54.58 \%$ of the cases $(N=137)$ showing that more than half the participants were thinking about leaving the $\mathrm{PhD}$ program.

3.2.1. Model testing. Given these results, we verified the two mediation models reported in figure 1 by the use of SEM. Therefore, the observed variables comprised four latent variables, namely, P-E misfit, mental disorder symptoms, intention to quit and meaningful work. Before verifying the hypotheses of the mediation role of meaningful work, hypotheses of the association between P-E misfit and mental disorder symptoms (H1a) and intention to quit (H1b) were tested.

P-E misfit positively predicted the level of mental disorder $\left(X^{2}(8)=28.061, p<.001\right)$ with a standardized coefficient effect equal to $\beta=.50$ and an explanation of the total variance equal to $\mathrm{R}^{2}=.24 \%$. Likewise, P-E misfit positively predicted the level of intention to quit $\left(X^{2}(2)=9.104, p<.011\right)$ with a standardized coefficient effect equal to $\beta=.45$ and an explanation of the total variance equal to $\mathrm{R}^{2}$ $=.45 \%$. Given the verification of $\mathrm{H} 1 \mathrm{a}-\mathrm{b}$, we verified the hypotheses $\mathrm{H} 2 \mathrm{a}-\mathrm{b}$. In the first case, we analyzed the mediation role of meaningful work within the association between P-E misfit and mental disorder. Given the path between P-E misfit equal to zero in a partial mediation $\left(X^{2}(12)=46.82, p<.000\right)$, we tested a full mediation where meaningful work that resulted, $X^{2}(13)=69.421, p<.000$. Here, meaningful work negatively mediated the relation by decreasing the overall level of mental disorder with a standardized coefficient equal to $\beta=-.28$ and total variance of $\Delta \mathrm{R}^{2}=.05$. Likewise, hypothesis $\mathrm{H} 2 \mathrm{~b}$ was tested by firstly analyzing a partial mediation where the path between P-E misfit and intention to quit resulted to be null, $X^{2}(4)=24.380, p<.000$. Then, meaningful work negatively mediated the relation between the association by decreasing the overall level of intention to quit with a standardized coefficient equal to $\beta=-.33$ and a total variance of $\Delta \mathrm{R}^{2}=.03, X^{2}(5)=37.746, p<.000$.

Figure 1. Graphical depiction of the hypothesized two mediation models with meaningful work as mediator.

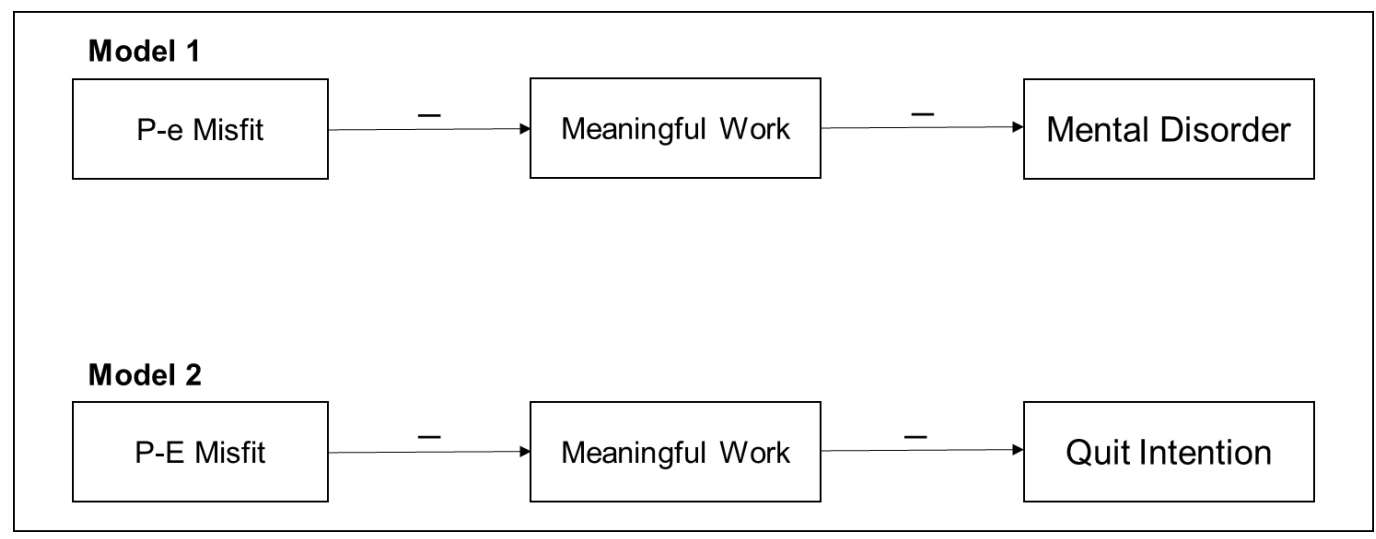

\section{Discussion}

The turbulent time for work and employability of the first decade of the third millennium has witnessed heightened the attention of researchers and policymakers to address the higher training programs for higher qualified workers and researchers as it is the case of $\mathrm{PhD}$ programs. Such concern is still urgent in the view of the current amount of mental problems in work and organizational settings and 
the academic sector. According to the evidence present in the literature, in the present study PhD students revelled to have a higher presence of mental symptoms suggesting the need for addressing their mental and physical health under the framework of well-being promotion at work (Bakker \& Oerlemans 2011). Moreover, the level of quit intention suggests a further need of research in the comprehension on how to keep students both in their current career development and for the future of research (Levecque et al. 2017). Our study suggests that mental issues and quit intention are mainly related to the level of the person-environment misfit. For instance, that is the case of a student who perceives a lack (a) of coherence between their goals and the goals of the job itself, where the job is intended in reference of the contextual organization of tasks and their direction. Additionally, students can experience a lack of sense of belonging to their organization as well as a lack of coherence between their goals and those of the university/institutions where their work. Still, given the evidence of the supervisors in shaping the emotional experiences at work (Sverdlik et al. 2018), a perception of misfit between students and their supervisor can conduct to the rise of mental disorder symptoms as well as to the loss of motivation and intention to quit.

Based on the data collected and the analysis, the preliminary findings of the study reveals promising opportunities for $\mathrm{PhD}$ programs and $\mathrm{PhD}$ students' mental health, given the role of meaningful work in significantly reducing the level of mental disorders symptoms and intention to quit. Indeed, meaningful work indicates the extent to which individuals perceive and experience that their work is meaningful. Such results indicate that the level of meaningfulness in work among students is widely present, suggesting that possible training intervention might be focused on the individual experience as well as policy makers might address contextual conditions that compromise the PhD students experience.

\section{References}

Allan, B. A., Batz-Barbarich, C., Sterling, H. M., \& Tay, L. (2019). Outcomes of meaningful work: A meta-analysis. Journal of Management Studies, 56(3), 500-528.

Bakker, A. B., \& Oerlemans, W. (2011). Subjective well-being in organizations. The Oxford handbook of positive organizational scholarship, 49, 178-189.

Bluedorn, A. C. (1982). A unified model of turnover from organizations. Human relations, 35(2), $135-153$.

Chuang, A., Shen, C. T., \& Judge, T. A. (2016). Development of a Multidimensional Instrument of Person-Environment F it: The Perceived Person-Environment Fit Scale (PPEFS). Applied psychology, 65(1), 66-98.

Euroscinetis (2018). Increasing awareness of researcher mental health. Euroscientist. Retrived on December $7^{\text {th }}, 2020$, from: https://www.euroscientist.com/increasing-awareness-of-researchermental-health/

Lauver, K. J., \& Kristof-Brown, A. (2001). Distinguishing between employees' perceptions of person-job and person-organization fit. Journal of vocational behavior, 59(3), 454-470.

Levecque, K., Anseel, F., De Beuckelaer, A., Van der Heyden, J., \& Gisle, L. (2017). Work organization and mental health problems in PhD students. Research Policy, 46(4), 868-879.

Nature Editorial (2018). Feeling overwhelmed by academia? You are not alone. Nature Careers Blog. Retrived on December $7^{\text {th }}, 2020$, from: https://www.nature.com/articles/d41586-018-04998-1

Rosso, B. D., Dekas, K. H., \& Wrzesniewski, A. (2010). On the meaning of work: A theoretical integration and review. Research in organizational behavior, 30, 91-127.

Schnell, T., \& Hoffmann, C. (2020). ME-Work: Development and Validation of a Modular Meaning in Work Inventory. Frontiers in Psychology, 11, 3405.

Steger, M. F., Dik, B. J., \& Duffy, R. D. (2012). Measuring meaningful work: The work and meaning inventory (WAMI). Journal of career Assessment, 20(3), 322-337.

Su, R., Murdock, C. D., \& Rounds, J. (2015). Person-Environment fit. In P. J. Hartung, M. L. Savickas, \& W. B. Walsh (Eds.), APA Handbook of Career Interventions (pp. 81-98). Washington, DC: American Psychological Association.

Sverdlik, A., Hall, N. C., McAlpine, L., \& Hubbard, K. (2018). The PhD experience: A review of the factors influencing doctoral students' completion, achievement, and well-being. International Journal of Doctoral Studies, 13, 361-388.

Tommasi, F., Ceschi, A., \& Sartori, R. (2020). Viewing Meaningful Work Through the Lens of Time. Frontiers in Psychology, 11.

Tommasi, F., Sartori, R., Ceschi, A., \& Schnell, T. (under review). The Meaning in Work Inventory: 875 Validation of the Italian Version and its Association with Sociodemographic Variables.

Ward, A. M., \& Brennan, N. M. (2020). Developing a student-doctoral education fit analytical model to assess performance. Studies in Higher Education, 45(7), 1448-1460. 